\title{
Enabling Knowledge Sharing Through Intrinsic Motivation And Perceived IT Support
}

\author{
Vikas Agrawal; Fayetteville State University \\ Shahnawaz Muhammed; Fayetteville State University \\ Ashish Thatte; Gonzaga University
}

\begin{abstract}
Knowledge is currently viewed as a key organizational resource to gain and sustain competitive advantage. Having the right knowledge at the right time to take effective action has become ever more critical for organizations. A key aspect of achieving this is by promoting conditions that enable organizational members to share their knowledge in the most effective manner. This research investigates the impact of knowledge workers' intrinsic motivation and their perceived usefulness of information technology support on knowledge sharing. The proposed model is tested using data from a sample of 252 knowledge workers in manufacturing and related industries. Results support proposed hypotheses suggesting that knowledge workers intrinsic motivation and perception of usefulness of information technology support positively affects knowledge sharing. Intrinsic motivation also affects knowledge sharing indirectly by enhancing knowledge workers' perception of information technology they use to share knowledge. This research underscores the importance of individual characteristics such as motivation and employee perception in sharing knowledge.
\end{abstract}

Keywords: Knowledge Management, Intrinsic Motivation, Perceived IT Support

\section{INTRODUCTION}

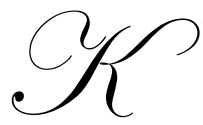

nowledge sharing is identified as one of the most critical factors to a company's success (Davenport and Prusak, 1998). It leads to faster deployment of knowledge to the critical portions of the organization so that sound strategic decisions can be made, ultimately contributing to the competitive advantage of the organization. It provides a link between the level of individual knowledge worker, where knowledge resides and the level of the organization, where knowledge attains it economic and competitive value (Kim, 1993; Hendriks 1999). The potential benefits of knowledge sharing for the organization are clear: knowledge is spread through the organization, it can be used for innovative services or products, the wheel is not re-invented, products and services may be of higher quality, and customers will be more satisfied (vonKrogh, 1998; APQC, 1999).

While being recognized as one of the important pillars of knowledge management, reports show that knowledge sharing imposes significant barrier for effective implementation of knowledge management practices. Various factors have been sited for the impediments of knowledge sharing, including inadequate organization structure, sharing-unfriendly organization cultures, and denominational segregation (Davenport and Prusak, 1998; Tissen, Andriessen and Deprez, 1998). Also at times people who have knowledge may not be conscious of what they know or how significant it is, or they might not be able or willing to share it with other people. Even when they are willing, the readiness to accept the wisdom of others is not so obvious. Thus knowledge is "sticky" and tends to reside in people's heads. One of the major concerns is the issue whether or not knowledge workers are motivated to share their knowledge with others. Knowledge worker's motivation plays a critical role in enabling sharing of tacit as well as explicit knowledge (Stenmark, 2001; Tuomi 2001). 
Another important enabler of knowledge sharing in an organization is the information technology, which empower the individual knowledge worker by providing the tools to support and boost his or her knowledge-sharing skills (Tampoe, 1996). Technologies like electronic databases, audio and video recordings, interactive tools and multimedia presentations help to captures and disseminate knowledge through out the organization. Low cost communication systems such as intranets, collaborations systems, or groupware applications can enhance knowledge sharing with in the company and across the entire supply chain by virtually eliminating temporal and special barriers. However, user's perception of technology, its acceptance, and subsequent satisfaction has been widely researched in the literature and is a critical aspect of understanding the use of technology for any application (Davis, 1989; Venkatesh, 2000; Doll \& Torkzadeh, 1988).

This research investigates the role of workers' intrinsic motivation on knowledge sharing and the possible impact of such motivation on knowledge workers' perceived IT support. We also explore the impact of knowledge workers' intrinsic motivation on their perception of IT support. Perceived IT support as viewed in this research is the knowledge worker's perception of the usefulness of information technologies they use for knowledge sharing.

In the next section we explore the literature on knowledge sharing and define knowledge sharing from an individual perspective. The three subsections following this examine the relationship between the intrinsic motivation, perceived IT support, and knowledge sharing and present the specific hypotheses and research model. Section 3 presents the research methods, followed by the results of the data analysis in section 4 . The results are presented in subsequent subsections for measurement assessment and structural model tests. Finally, we present the conclusion with implications and directions for future research.

\section{KNOWLEDGE SHARING}

Knowledge sharing is probably one of the most important activities in knowledge management process (Gibbert and Krause, 2002). It is defined as an act of deploying individual and collective organizational knowledge to those important areas of organization where people needs it most and make effective use of that knowledge in taking actions and making decisions (Hendriks, 1999). Knowledge sharing provides a link between individuals that possess know-how and the organization where that knowledge achieve its social and economic values, which in terms leads to overall organization learning.

Knowledge sharing is also one of the key aspects of the success or failure of many knowledge management initiatives. If employees are not willing or able to share what they know with other organizational entities, rest of the knowledge management initiatives are not likely to be very fruitful. There are many factors that can impede knowledge sharing such as lack of trust, unfriendly environment, lack of time, and failure to understand the importance of others knowledge (Davenport and Prusak, 1998). It is often argued that knowledge is not a commodity that can be freely passed from one subject to another; rather it is tied to the knowing subject. From this perspective, to transfer knowledge from one person to another, the recipient body needs to reconstruct the received information. The first person possessing the knowledge should first share the knowledge, willing or not willing, in some form such as by acts, speech, writing or some other means. Person willing to acquire knowledge should be able to perceive these expressions of knowledge and should be able to make sense of it (Hendriks, 1999; Boland \& Tenkasi, 1995). 


\section{External World}

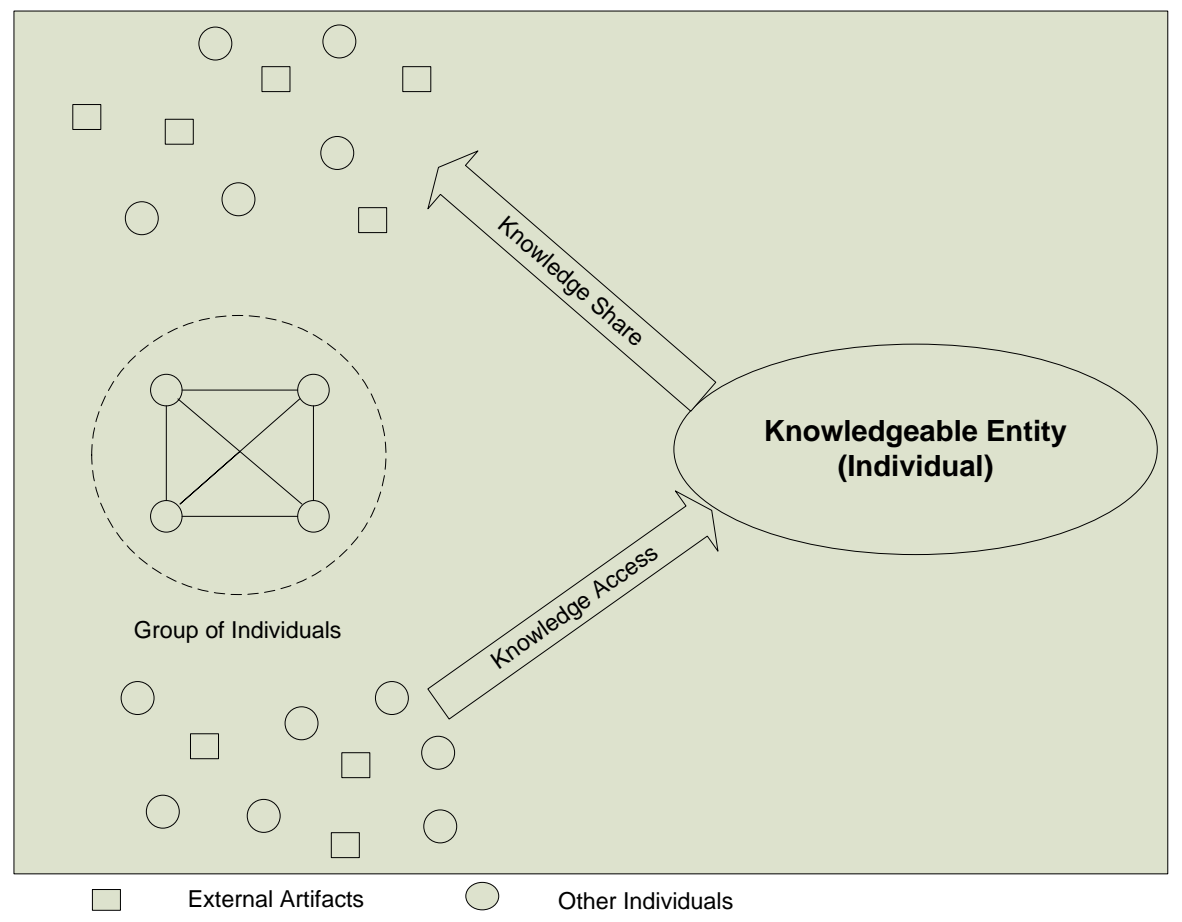

Figure 1: Knowledge Sharing from an Individual Perspective

Other discussions on knowledge sharing in many discourses center on whether it is the knowledge or the information that is actually shared. This is essentially linked to the more basic definition of knowledge itself and is an issue when knowledge sharing is viewed from an organizational perspective because, whether knowledge can reside external to the individual has been heavily contended. However, such a perspective external from the individual implies two distinct processes in knowledge sharing. One is involved in giving out one's knowledge or knowledge donation, and the other is involved in the collection of knowledge from external entities (Van den hoof and De Leeuw van Weenen, 2004). In individual level studies, these two are two distinct processes, and different factors may impact the extent to which one is willing or able to share one's knowledge and the ability to retrieve or access this information by the receiving party. Consistent with the former process indicated above as the act of giving out one's knowledge, we define and limit knowledge sharing in this context as the specific act of externalizing one's knowledge (Figure 1).

Knowledge transfer can occurs at various levels within an organization, such as transfer of knowledge between individuals, from individuals to explicit sources, from individuals to groups, between groups, across groups, and from the group to the organization (Alavi and Leidner, 2001). Transfer of knowledge at the various levels are facilitated by various channels such as formal or informal channels, and personal or impersonal channels (Holtham and Courtney 1998). Each channel has its own advantages and disadvantages. Informal mechanisms, such as informal seminars, coffee break conversations, unscheduled meetings, may be effective in promoting socialization but may preclude wide dissemination. Formal transfer mechanisms such as training sessions and plant tours may ensure greater distribution, but may restrict creativity. Personal channels, such as personnel transfer, may be more effective for sharing highly context specific knowledge where as impersonal channels, such as knowledge repositories, may be most effective for knowledge that can be readily generalized to other contexts (Alavi and Leidner, 2001). However, all of these various levels of knowledge sharing that occurs through different channels are increasingly facilitated by information technologies. 


\subsection{Intrinsic Motivation And Knowledge Sharing}

There are various approaches to motivation in the literature however, most motivational theories deal with a set of circumstantial forces that make people behave in a particular way, indicating various factors and mechanisms behind their feelings and actions. Social and organizational psychologists have studied this phenomenon intensively and have theorized on the various mechanisms of motivation. Traditionally, there are two types of motivation theories: content theories that focus on WHAT incentives (and needs) lie at the basis of motivated behavior and process theories that specify HOW needs, incentives, expectations and intentions combine to result finally into behavior. For full understanding of the motivation theories, one needs to see it from both content and process perspective.

Content theories identify different kinds of factors (incentives) that drive human behavior, generally without specifying how this driving process actually works. There are two types of incentives discussed in the literature i.e., intrinsic and extrinsic incentives (Herzberg, 1968). Always there is a search for a parallel between certain intrinsic needs of the people and external factors (incentives, rewards) that satisfy those needs. Several content-based motivation theories can be found in the literature (Alderfer, 1972; Maslow, 1968; McGregor, 1960; Herzberg, 1968; McClelland, 1971; and Vroom, 1964). These theories when combined present a wide variety of individual motivation factors.

Maslow's (1968) theory is one of the most widely used motivational theories in business. It points to the existence of many individual needs, which are clustered into five categories: physiological needs (e.g. food, water sex), need for security (e.g. safe working environment), need for belongingness (e.g. love, affection), need for recognition, status, and power (e.g. self-esteem, self-respect, respect from others), and need for self-actualization (e.g. reach one's full potential). The theory further contains a hierarchy principle - the latter needs can only become motivational when former needs are satisfied.

In spite of its high popularity, Maslow's theory is often criticized because of the strict adherence to the hierarchy of needs, relatively lesser emphasis on the behavior within the hierarchy, and its weaker empirical foundation (Alderfer 1972, Maccoby, 1988). However, it is applicable in understanding knowledge sharing as in many other areas because, people might share knowledge to gain higher social status, reputation and power, to increase their knowledge base, to help others, to increase their abilities and to protect their job. These factors could motivate the individuals to share knowledge.

Another widely used, empirically strong, motivational theory is Herzberg's (1968) two-factor theory. Herzberg's two-factor theory is based on the distension between motivator factors and hygiene factors. Herzberg concluded from his studies concerning performance motivation that the factors in the need gratification theories do not all have the same function. He pointed out that some factors are real drivers of behavior, others function more as a kind of barrier. He distinguished between motivation factors and maintenance or hygiene factors. Motivator factors are factors such as achievement, responsibility, recognition, operational autonomy, promotional opportunities and challenge of work. Hygiene factors are factors such as good salary, high status, sound company policy and good interpersonal relations. Hygiene factors affect the motivation in a roundabout, primarily negative manner. Their presence might not lead to increase in motivation level, but if absent might affect motivation negatively (Hendriks, 1999).

While content theories focuses on the basic human needs, and intrinsic and extrinsic motivation factors, process theories focus on the very process of motivation itself i.e. the interrelationships between the intrinsic and extrinsic motivation factors, and the environment which shape particular human behavior. Process theories of motivation include theories such as Adams' equity theory (Adams 1965), Vroom's expectancy theory (Vroom, 1964), goal-setting theory, and reinforcement theory.

Expectancy theory is particularly important in the context of knowledge sharing. The basic foundation of expectancy theory is that the intention to act in a particular way not only depends on the attractiveness of certain incentives as identified by content theories, but also on the expectation that such behavior, e.g. sharing knowledge, 
will indeed reap those attractive outcomes. The actual behavior of people is then a function of people's intention (what they want), their competencies (what they themselves do) and the situational constraints (what environment allows them to do).

H1: Greater the intrinsic motivation of the individuals greater will be their knowledge sharing.

\subsection{Intrinsic Motivation And Perceived Information Technology Support}

Information technology is as an integral part of life in today's more knowledge oriented and emergent work. It has lead companies to imagine a new world of leveraged knowledge. Email systems coupled with the Internet have allowed knowledge workers to share information and ideas with peers no matter where they are located. Technologies like decision support systems and management information systems allow managers to dig out the hidden knowledge, see the patterns of business trends, and make effective decisions. Databases allow companies to organize the data that will lend itself for easy and faster data searching and retrieval with minimal duplication. Knowledge management systems and document management systems allow companies to capture and store past experiences in the form of best practices so that other could draw from existing knowledgebase and avoid reinventing wheel.

However, reports have shown that all too often even the implementation of best technology does not result in significant improvement of organizational performance. Many factors may affect the successful implementation and use of technology. The factors that we are focusing on are the perception of people using technology and their motivation level. Knowledge workers will only use technology if they perceive it as useful and effort-free. In other words, if knowledge workers do not perceive any software as useful then even the best technology will be a failure. There are many theories available in the literature to deal with the information systems usage. One such theory is the Technology Acceptance Model (TAM) (Davis, 1989) that models how users come to accept and use a technology. TAM model suggest that when users are presented with new software, many factors will influence their decision about how and when to use such systems. The two predominant factors sited in the TAM model are perceived usefulness and perceived ease-of-use (Davis, 1989).

Davis in his TAM model has used user perception of ease of use of technology and technology usefulness in the context of IT adoption. We are capturing user perception of available IT support in the specific context of knowledge sharing. If knowledge workers perceive the available technology as useful for sharing knowledge, then they will tend to use it more for sharing their knowledge with other people. More support for this could be found in Section 2.3.

Though TAM model talked about the factors that affects users decision about how and when to use technology, it does not talk about how exactly this perception is formed and changes overtime. Venkatesh (2000) proposed and empirically tested the determinants that affect the perceived ease of use of technology. He indicated that some factors act as an anchoring when it comes to shaping the perceived ease of use, which include computer self-efficacy, perception of external control, computer anxiety and computer playfulness, while others acts as adjustments as a result of continuous user-system interaction, which include perceived enjoyment and objective stability.

The relationship between computer playfulness, which is defined as the degree of cognitive spontaneity in microcomputer interactions, and perceived ease of use in Venkatesh's (2000) study is proposed based on the motivation theories. However, computer playfulness is a task specific and narrow conceptualization of motivation that was found to have a significant impact of the perceived ease of use. Task specific motivational factors, such as computer playfulness are influenced by more global motivational states of individuals (Thomas \& Velthouse, 1990). These global intrinsic motivations of individuals, which differentiate between individuals who are generally motivated and enthusiastic to do their work and others who are not, have a more pervasive and lasting effect of their attitude towards work and find work to be more meaningful. We hypothesize that such global intrinsic motivation has a significant positive impact on the perception of the usefulness of information technology that is available to these individuals. 
H2: Greater the intrinsic motivation of the individuals greater will be their perception of the usefulness of Information Technology Support.

\subsection{Perceived Information Technology Support And Knowledge Sharing}

An effective organization comprises of a constellation of interconnected processes and systems, each dealing with specific aspect of company's competency. The value of these processes and systems are realized through their continual use and improvements by knowledgeable entities at all levels within the organization. The individuals who create, contribute to, and use these systems and processes are continually in interaction with the various organizational entities. They make-sense of the environment in which they operate and share that understanding by appropriate actions or communication. This is the fundamental way in which an organization grows its intellectual resource (Kim, 1993). For both large and small companies, these intellectual assets typically provide the foundation to create value for their customers and stakeholders.

In managing such intellectual resources, organizations are recommended to follow either a codification or a personalization strategy depending upon its broader competitive strategy (Hansen, Nohria \& Tierney, 1999). Codification strategy is appropriate for organizations that create value primarily by taking advantage of information reuse and are generally information system intensive whereas, the personalization strategy is advantageous for organizations that focus on highly customized products or services and is traditionally considered as less information system intensive. However, today's information systems are becoming increasingly flexible in that they accommodate a certain amount of variation regarding the requirements of the supported business process and personal need. Today's information systems also help to embed highly specialized knowledge into computer routines and thereby making widespread dissemination possible. Traditionally, it was believed that only knowledge pertaining to low-skilled job could be embedded into technology, but now because of technological advancement it is increasingly becoming possible to embed higher levels of knowledge using technology (Davenport \& Glaser, 2002).

However, having access to even the best available technologies might not be effective to accomplish knowledge sharing objectives unless knowledgeable entities in organization perceive them as useful. The potential of what modern information technologies make it possible is realized only to the extend knowledge workers in organization perceive their values and use them effectively. Thus effective use of technology is a function of both the available technology and people's perception of it. Having effective technology can contribute to it being perceived positively (Muhammed \& Agrawal, 2007), and the various individual characteristics can also effect this perception, including their motivation.

Torkzadeh and Doll (1999) content that "In today's end-user computing environment, the natural concern over how well designed information systems are must be augmented with an equally ardent concern about how effectively they are used or what impact they have on work" (p.328). In the post-industrial era, characterized by knowledge work, work is heavily dependent on information processing and is also increasingly abstract (Doll and Torkzadeh, 1998; Hirschhorn, 1984). In such a context, Doll and Torkzadeh, (1998) identify decision support, work integration, and customer support as three main functions of IT. These three dimensions imply that knowledgeable entities in the work place need to communicate their task related knowledge effectively using these technologies to achieve the desired results.

Modern IT tools can foster both tacit as well as explicit knowledge sharing and need not be seen as an enabler of processes dealing with explicit knowledge alone (Riggins \& Rhee, 1999; Scott, 1998). Alavi and Leidner (2001) suggest that as information exposure increases through intranets and other computer networks, individual may create greater knowledge. This clearly means that users perceive such technology as important enabler for sharing knowledge among knowledgeable entities. Probably it is the collective group of technologies, which includes data processing technologies like Word and Excel, data storage technologies like databases, data analysis technologies like data warehouse and data communicating technologies such as internet, intranet and extranet that gives knowledge workers abilities to create, store and share knowledge with other external entities. This occurs 
primarily when individuals who use these technologies internalize and recognize the capabilities of these technologies and apply them in their work.

Just as the ability of a group is greater than the sum of the capabilities of the individuals in that group, the knowledge of the group is also considered greater than the sum of the knowledge of its individual members. However, this social knowledge is critically dependent on the ease of interaction between the individuals in such a group. Ruggles (1997) identify various information technologies that could be used for knowledge transfer based on barriers such as temporal, physical and social. Information technology may be very effective in lowering these barriers in knowledge sharing. Technologies such as groupware, internet-based discussion group and electronic meeting software allows geographically dispersed group of people to form a virtual team and collaborate online and real-time on common specific goals. This virtually eliminates both temporal and physical barriers. Information technology may also be helpful in lowering some part of social barriers as well, for example, providing tools that facilitates social translation such as learning maps (Ruggles, 1997; Huber, 1991).

Information technology can help in knowledge transferring by increasing individual's reach beyond the formal communication lines. The search for knowledge sources is usually limited to the immediate coworkers in regular and routine contacts. Coworkers tend to have knowledge that is limited to the same domain which could further restrict the quest for new knowledge reach (Robertson \& Swan, 1996). Computer networks, electronic bulleting boards and discussion groups may form a forum that facilitates the contacts between persons seeking knowledge and persons having access to the knowledge (Alavi and Leidne, 2001).

Today's IT applications have also become broader and multifaceted, and incorporate more functionalities than ever that allow knowledge worker to use them in more flexible and interpretive ways depending on the their needs (Orlikowiski, 2000). From a knowledge management perspective, today's IT applications support many functions related to managing one's knowledge such as stimulating one's thinking to create new knowledge, sharing one's insights, retrieving information from various sources, and applying their knowledge to automate parts of their work.

As work become more emergent and knowledge oriented with increasing interface with IT, there is a greater significance in how individuals perceive these technologies as useful and what they can do (DeSantis \& Poole, 1994; Orlikowski, 2000). As individuals who use these technologies realize the various ways and levels at which their knowledge can be shared, they are drawn to using these capabilities to reap their advantages and share their knowledge more effectively.

H1: Greater the perceived usefulness of information technology support, greater will be the knowledge sharing.

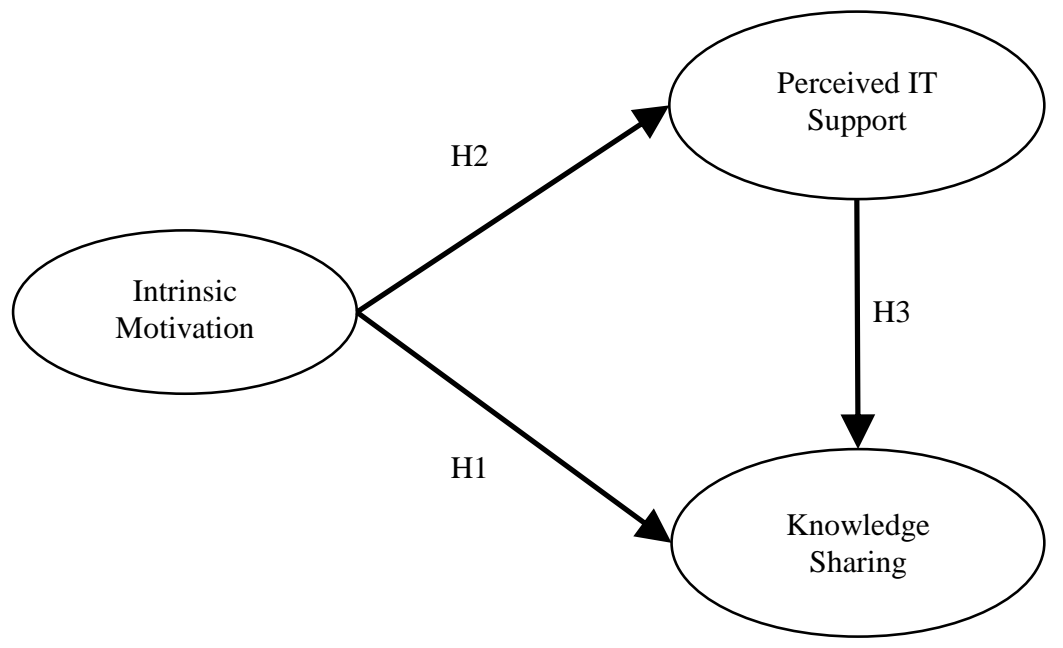

Figure 2: Theoretical Model 


\section{RESEARCH METHODS}

A cross-sectional survey design method is used to test the model and the hypothesized relationships. Large scale data collection was preceded by pretest and a pilot survey to assess the measurement instruments. Measures for perceived usefulness of IT and knowledge sharing were newly developed based on generally accepted psychometric principles (Churchill, 1979; Netemeyer et al., 2003). Intrinsic motivation was based on Spreitzer's (1995) meaning dimension of empowerment. All measures were validated and assessed for clarity in the pretest with ten individuals comprising of experts in the field and target respondents.

Following the pretest of the items and refinement, measures were further refined by conducting a pilot test. Pilot test involved small scale data collection and assessment of validity, dimensionality and reliability of the scales. Subsequently, large scale data collection targeting managerial and professional knowledge workers were implemented using a web-based questionnaire. The following sections briefly describe the pilot, large scale and measurement development. Structural equation modeling using LISREL is employed for measurement assessment and for testing the structural model and hypotheses testing.

\subsection{Pilot Testing}

A pilot test was performed based on 53 responses obtained out of the 68 survey requests. 24 responses were received from the individuals working in various functions within a few mid-west organizations involved in design, manufacturing or consulting for other manufacturing and engineering firms and the rest of 29 responses were received from primarily MBA students most of whom were working in various positions in the industry similar to our target respondents. Individuals were identified as knowledge workers who used information technology heavily for their daily work, by the managers in their respective organizations that agree to participate in this research. The pilot stage data analysis involved item purification using corrected item-total correlation (CITC) scores, evaluation of unidimensionality using principal component factor analysis (Netemeyer et al., 2003), evaluation of convergent and discriminant validity using structural equation modeling (Bagozzi \& Phillips, 1991) and reliability assessment using Chronbach's (1951) alpha. Items pertaining to each construct were modified or eliminated based on the feedback from the pilot results.

\subsection{Large Scale Sample}

To implement the large scale data collection, a web based survey was implemented. An email list from Manufacturer's News Inc targeting managerial knowledge workers were used to reach the target respondents. Website implemented tracking of click-through based on the email invitations requesting to complete the survey online. After administering two waves of emailing, 252 usable and complete responses were obtained yielding a $31.6 \%$ response rate based on click-through. Respondents included individuals from a wide rage and size of industries. Majority of the respondents were professionals or in middle management or above positions. Nonresponse bias was evaluated using a Chi-square test of goodness-of-fit of various demographic variables between the first and the second wave of data collection (Smith, 1983). The results indicated that no significant difference existed between various demographic variables and were non-significant at $\mathrm{p}$-values above 0.10 . Measures were evaluated in steps similar to the pilot stage involving item purification, evaluation of factor structure, unidimensionality, and convergent and discriminant validity.

\subsection{Measures}

Respondents were asked to respond to the survey items based on a particular project or an assignment, or to reflect on the last six months of their work if they did not typically work on projects. For IT support and knowledge sharing a five point Likert type scale where $1=$ None or to a very little extent and $5=$ To a very great extent was used. To respond to IT support items, respondents were asked to think of 3 main software applications they had used during the referent time frame and to base the responses on these applications. The actual items were worded, for example, as "the above applications were helpful in communicating what I know". Knowledge sharing had items such as, "during the assignment/project/work, I have shared my insights with others". For intrinsic motivation, a 
seven point Likert type scale ranging from $1=$ Not at all and $7=$ To an exceptionally great extent, is used. This measure used a seven point scale because it was based on an existing measure of meaning dimension in Spreitzer's (1995) empowerment construct. The items in this section were slightly modified to fit the referent framework of the current study. The common part of each item was separated from the set of items and was presented as the leading text for those set. Separating these leading texts from the main content of the items enabled the respondents to focus on the essential elements of the question and at the same time creating the right frame of reference before answering each item. The final measures had four items for IT Support, four items for knowledge sharing, and three items for intrinsic motivation. The final items for each construct after purification and measurement analysis is listed in Appendix A.

\section{RESULTS}

Data analysis is performed in a two step process where first the measurement model is evaluated followed by the analysis of structural model to evaluate the hypotheses (Anderson and Gerbing, 1988). In the first step, descriptive statistics are presented along with the analysis of reliability, convergent validity and discriminant validity of the measures. Next, the structural model is evaluated using LISREL to test the three substantive hypotheses.

\subsection{Measurement Model Results}

Evaluation of CITC scores for each construct at this stage indicated good CITC values for their respective items and where all above the recommended 0.60 cutoff score. Next, to test for unidimensionality, each scale was factor analyzed separately with their corresponding items. All items for the respective scales loaded on a single factor and had a factor score above 0.60 indicating unidimensionality. To assess the convergent and discriminant validity, first all items were factor analyzed together (Table 1). Following which, the measurement models of each construct were analyzed in a pair-wise fashion in LISREL. The indicators were also tested for univariate normality. The skewness values are between -2 and +2 and the kurtosis values are all lower than 5.0, providing evidence that the scales are normally distributed (Hair et al., 1998).

Table 1: Results of Factor Analysis

Pattern Matrix ${ }^{a}$

\begin{tabular}{|l|r|r|r|}
\hline & \multicolumn{3}{|c|}{ Factor } \\
\cline { 2 - 4 } & \multicolumn{1}{|c|}{1} & \multicolumn{1}{c|}{2} & 3 \\
\hline IMOT3 & .983 & & \\
IMOT2 & .955 & & \\
IMOT1 & .910 & & \\
PRIT3 & & .956 & \\
PRIT2 & & .932 & \\
PRIT1 & & .864 & \\
PRIT4 & & .834 & .934 \\
KSHR3 & & & .930 \\
KSHR2 & & & .886 \\
KSHR4 & & & .806 \\
KSHR1 & & & \\
\hline
\end{tabular}

Extraction Method: Maximum Likelihood.

Rotation Method: Oblimin with Kaiser Normalization.

a. Rotation converged in 5 iterations. 
The factor analysis of the items with maximum likelihood estimation and oblimin rotation yielded three factors with no crossloadings above 0.30 indicating sufficient discrimination between the scales. All the items corresponding to each construct loaded on their respective factors with a factor loading greater than 0.80 (KSHR1) indicating evidence for good convergent validity (Table 1).

Next, an individual measurement model was constructed for each construct with their respective items loading on the construct to evaluate the model-data fit. This would also enable us to identify any extreme cases of correlated errors between the items within the construct. This may be further used to examine the cause of such error correlations in the light of available theory and could be used to either account for such error correlations in the model or eliminate an item in consideration for the parsimony of the measurement model. IT support had two error correlations. However, upon examination of the items there were no justification to have an error correlation from a theoretical perspective and hence no action was taken. The modification indices for the error correlations were also not very high (larger error correlation had a modification index of 8.32). Measurement models in this section indicated good fit. The p-values were non-significant above 0.01 level for all the three constructs.

To further access the convergent and discriminant validity all constructs were subjected to pair-wise comparison in LISREL. The results are shown in Table 2, which includes the average variance extracted (AVE), Pearson correlation between the constructs $(r)$ and the reliabilities $(\alpha)$. The chi-square difference between the models with construct correlations set to free and set to one ranges from 614.14 to 948.13 indicating good discriminant validity. Correlation of a scale with another scale below 0.70 is also generally accepted as a good indication of discriminant validity (Ping, 2004). Correlation of the scales rages from 0.28 to 0.49 suggesting discriminant validity between the measures. Another good measure of convergent validity in mono-method studies is Fornell and Larker's (1981) AVE (Ping, 2004). AVE can range form 0 to 1 , but a value above 0.50 indicates adequate convergent validity for the construct, and indicates that the measures contain less than $50 \%$ of error variance (Fornell and Larker, 1981). AVE for the measures in this section ranges form 0.79 to 0.90 indicating excellent convergent validity (Anderson \& Gerbing, 1988).

Table 2: Reliability, Convergent Validity and Discriminant Validity of Latent Variables.

\begin{tabular}{|l|l|l|l|}
\hline & Intrinsic Motivation & IT Support & Knowledge Sharing \\
\hline \multirow{3}{*}{ Intrinsic Motivation } & $\mathrm{AVE}=0.90$ & & \\
\cline { 2 - 4 } IT Support & $\alpha=0.97$ & & \\
\hline \multirow{3}{*}{ Knowledge Sharing } & $r=0.28^{* *}$ & $\mathrm{AVE}=0.81$ & \\
\hline Mean $=$ & $\chi^{2}=948.13$ & $\alpha=0.94$ & $\mathrm{AVE}=0.79$ \\
\hline SD $=$ & $r=0.32^{* *}$ & $r=0.49^{* *}$ & $\alpha=0.94$ \\
\cline { 2 - 4 } & $\chi^{2}=614.14$ & $\chi^{2}=935.86$ & 3.89 \\
\hline Skewness $=$ & 5.71 & 3.79 & 0.88 \\
\hline Kurtosis $=$ & 1.31 & 1.04 & -0.855 \\
\hline$* *$ Correlation is significant at the 0.01 level (2-tailed). & -0.989 & 0.762 \\
\hline$\chi^{2}>8.62$ for 1 d.f. is significant at $\mathrm{p}$-value corrected for number of comparisons $(0.01 / 3)$. \\
\hline
\end{tabular}

Next, all the five measures were analyzed together as a correlated measurement model for model-data fit. The modifications indices suggested two error correlations, examination of the items did not reveal any explicit reasons for such error correlations to be specified in the model. Further, the largest modification index was only 11.05 for a cross loading between items in IT support and knowledge sharing. These were interpreted as not high modification indices given the size of the model and the sample size used for the analysis. Specifying the modifications in the model almost always provides a better fit with the data but when it is atheoretical they are not replicable in a different dataset (Hair et al., 1998). Chi-square value for the fully correlated model was 61.19 for 41 degrees of freedom and had a non-significant p-value (0.022). The ratios of chi-square to degrees of freedom (1.49) indicate good fit (March and Hocevar, 1985). Other fit indices evaluated in conjunction for the model-data fit also indicate good fit $(\mathrm{GFI}=0.96$, AGFI=0.93, $\mathrm{NFI}=0.98$, NNFI=0.99, CFI=0.99 and RMSEA=0.044). All items had 
good standardized item loadings on their respective constructs (above 0.82). All factor loading were also significant at $\mathrm{p}$-value $<0.001$.

\subsection{Structural Model Results}

The full structural model (see Figure 3) indicates good model-data fit with a chi-square of 61.19 for 41 degrees of freedom, chi-square per degrees of freedom $=1.49$, p-value $=0.022$, RMSEA $=0.044, \mathrm{NNFI}=0.99$, and $\mathrm{CFI}=0.99$. Evaluation of the modification indices suggested one error correlations between two items in IT support, between the same items observed in the measurement model. Since no plausible explanation was evident for the observed error correlation and its relatively low magnitude (8.74), this was assumed to be not a significant problem for the current model. It is possible that this is a spurious error correlation specific to this sample data. Figure 3 illustrates the structural relationships between the exogenous variable $(\gamma)$ intrinsic motivation and the endogenous variables $(\eta)$ perceived IT support and knowledge sharing. It also depicts the structural relationships $(\beta)$ between perceived IT support and knowledge sharing.

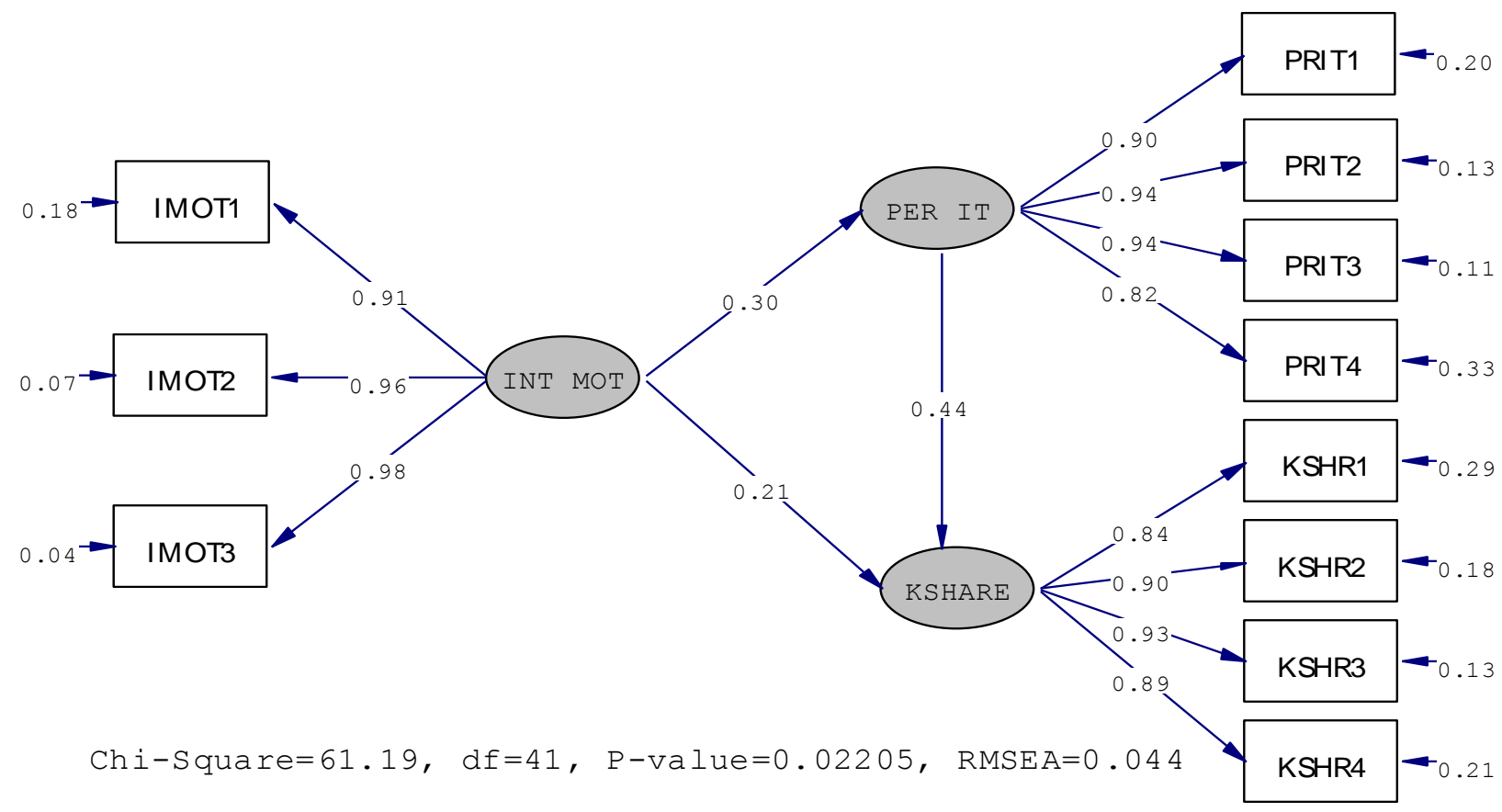

Figure 3: Standardized Path Coefficients of Full LISREL Structural Model (all loadings significant at p-value<0.001).

Next, the proposed hypotheses can be evaluated given the good model-data fit. Intrinsic motivation has a strong path coefficient to both knowledge sharing $(\gamma=0.21, \mathrm{t}=3.44)$ and perceived IT support $(\gamma=0.30, \mathrm{t}=4.56)$. Thus, hypothesis $\mathrm{H} 1$ and $\mathrm{H} 2$, indicating that motivated individuals will engage in higher levels of knowledge sharing and perceive information technologies they use to be more helpful are supported. Perceived IT support also has a significant path coefficient $(\beta=0.44, \mathrm{t}=6.64)$ knowledge sharing. Thus, hypothesis $\mathrm{H} 3$ is also supported indicating that more the knowledge workers perceive available information technologies as useful for sharing knowledge, more they will engage in the act of knowledge sharing.

All hypotheses proposed in this article were supported by the results of the data analysis. This research finds that intrinsically motivated individuals who view their work as meaningful engage in knowledge sharing to a greater extent. These individuals also perceive the information technologies they use to be more useful in the context 
of knowledge sharing. Results indicate that individuals who perceive the information technologies they use to be more useful for sharing knowledge also tend to share their knowledge to a greater extent.

\section{CONCLUSION}

Knowledge sharing has been cited as one of the most important initiatives of knowledge management that links the individual's knowledge where the knowledge resides and the organization's knowledge where it attains its social and economic value. Knowledge sharing allows quick deployment of individual and collective knowledge to various parts of organization which can be accessed by the people at will by eliminating location and temporal barriers. However, there are many barriers which can affect effective knowledge sharing.

One such important factor is worker's motivation. If workers are in general not motivated to work, there is no way one can see widespread sharing of knowledge in an organization. There are many factors cited in the literature for employee motivation that includes rewards - both monetary and non-monetary. In addition, the environment in which employees work also affect their motivation level to work. Factors such as friendly environment, less bureaucracy in hierarchy, open communication, encouragement from top management might help in building up right atmosphere that might increase motivation level of employees besides reward systems.

Another important enabler for effective knowledge sharing is the perceived IT support. If people perceive the available IT support as useful for sharing knowledge, then one can expect increased knowledge sharing among knowledgeable entities. Many factors could determine the perception of users including their knowledge, training and experience while using particular system to share knowledge and the interpretive flexibility that is built-in the technology. But IT is just a means to an end and not an end by itself. If people are not motivated to use these tools, even the best IT tool cannot produce the intended results when it comes to knowledge sharing.

In this research, we studied the relationship between intrinsic motivation, perceived IT support and their impact on knowledge sharing in manufacturing firms. We chose manufacturing firm as we believe that most of the knowledge work takes place in such organizations. Also we focus on knowledge sharing that happens at individual levels rather than at team or organizational level. We believe that it's the collective individual knowledge that shapes up the organization's overall knowledge.

All proposed hypothesis were supported by the result of data analysis. In the structural model, we found that intrinsic motivation had a strong path coefficient to both knowledge sharing (H1) and perceived IT support (H2). This implies that if employees are motivated in general, they tend to share more knowledge. They also tend to create positive perception of using available technology for sharing knowledge. We also tested the relationship between perceived IT support and knowledge sharing (H3) and found positive relationship between them. This could imply that if users perceive available IT support as useful for sharing knowledge, they tend to use such technology more to share knowledge with other people in the organization.

Further research could focus on expanding the model to incorporate other factors such as communities of practices like network ties, mutual trust, knowledge complexity and characteristics of work like work range and work structure. Our study mainly focused on manufacturing firms related organizations. Further research could focus on incorporating other types of industries in order to increase the generalizability of the findings.

\section{REFERENCES}

1. Adams, J. S. (1965). Inequity in social exchange. In L. Berkowitz (ed.). Advances in experimental social psychology. New York: Academic Press.

2. Alavi, M. \& Leidner, D. E. (2001). Knowledge Management and Knowledge Management Systems: Conceptual Foundations and Research Issues. MIS Quarterly, 25(1), 107-136.

3. Anderson, J. C. \& Gerbing, D. W. (1988). Structural Equation Modeling in Practice: a Review and Recommended Two-step Approach. Psychological Bulletin, 103(3), 411-423.

4. Alderfer, C.P. (1972). Existence, relatedness and growth. New York: Free Press. 
5. APQC (1999). Creating a knowledge-sharing culture. Houston, Texas: American Productivity and Quality Center.

6. Bagozzi, R. P., Yi, Y. \& Phillips, L. W. (1991). Assessing Construct Validity in Organizational Research. Administrative Science Quarterly, 36(3), 421-458.

7. Boland, R.J.J. \& Tenkasi, R.V. (1995). Perspective making and perspective taking in communities of knowing. Organization Science, 6(4), 350-372.

8. Cronbach, L. (1951). Coefficient Alpha and the Internal Structure of Tests. Psychometrika, 16, 297-334.

9. Churchill, G. A. J. (1979). A Paradigm for Developing Better Measures of Marketing Constructs. Journal of Marketing Research, 5, 64-73.

10. Davenport, T.H \& Glaser J. (2002). Just-in-time delivery comes to knowledge management. Harvard Business Review, 80(7), 107-111.

11. Davenport, T.H. \& Prusak, L. (1998). Working knowledge: how organizations manage what they know. Boston, Mass: Harvard Business School Press.

12. Davis, F.D. (1989). Perceived Usefulness, Perceived Ease of Use, and User Acceptance of Information Technology. MIS Quarterly, 319-340.

13. DeSanctis, G. \& Poole, M. S. (1994). Capturing the Complexity in Advanced Technology Use: Adaptive Structuration Theory. Organization Science, 5, 121-147.

14. Doll, W. J. \& Torkzadeh, G. (1998). Developing a multidimensional measure of system-use in a $\mathrm{n}$ organizational context. Information and Management, 33, 172-185.

15. Doll, W. J. \& Torkzadeh, G., (1988). The Measurement of End-User Computing Satisfaction. MIS Quarterly, 12(2), 259-274

16. Fornell, C. \& Larcker, D. F. (1981). Evaluating Structural Equation Models with Unobservable Variables and Measurement Error. Journal of Marketing Research, 18(1), 39-50.

17. Hair, J., Anderson, R., Tatham, R. \& Black, W. (1998). Multivariate Data Analysis, Upper Saddle River, New Jersey: Prentice-Hall, Inc.

18. Hansen, M. T., Nohria, N. \& Tierney, T. (1999). What's Your Strategy for Managing Knowledge? Harvard Business Review, 77(2), 106-117.

19. Hendriks, P. (1999). Why Share Knowledge? The Influence of ICT on the Motivation for Knowledge Sharing. Knowledge \& Process Management, 6(2), 91-100.

20. Herzberg, F. (1968). Work and the Nature of Man, London, Granada Publishing.

21. Hirschhorn, L. (1984). Beyond mechanization: Work and technology in a post-industrial age. Cambridge, MA: MIT Press.

22. Holtham, C. \& Courtney, N. (1998). The executive learning ladder: a knowledge creation process grounded in the strategic information systems domain. Proceedings of the 4th Americas Conference on Information Systems. Association for Information Systems, Baltimore: MD, 594-597.

23. Huber, G.P. (1991). Organizational learning: the contributing processes and the literatures. Organizational Science, 1(1), 88-115.

24. Kim, D. H. (1993). The Link between Individual and Organizational Learning. Sloan Management Review, 35(1), 37-51.

25. Netemeyer, R.G., Bearden, W.O. \& Sharma, S. (2003). Scaling Procedures: Issues and Applications, Thousand Oaks, CA: Sage.

26. Maccoby, M. (1998). Why Work: Motivating and leading the new generation, New York, Touchstone/Simon \& Schuster

27. Marsh, H. W. \& Hocevar, D. (1985). Application of Confirmatory Factor-analysis to the Study of Selfconcept: First- and Higher-order Factor Models and Their Invariance Across Groups. Psychological Bulletin, 97(3), 562-582.

28. Maslow, A.H. (1968). Towards a psychology of being. New York: Van Nostrand.

29. McClelland, D.C. (1971). Assessing Human Motivation, Morristown, General Learning Press.

30. McGregor, D. (1960). The Human Side of Enterprise, New York, McGraw-Hill.

31. Muhammed, S. \& Agrawal, V. (2007). Exploring Perception of Technology Usefulness as a Mediator between ICT Support and Knowledge Sharing, Journal of the Academy of Business and Economics, 7(2), $1-8$. 
32. Orlikowski, W. J. (2000). Using Technology and Constituting Structures: A Practice Lens for Studying Technology in Organizations. Organization Science, 11(4), 404-429.

33. Ping, R. A. J. (2004). On Assuring Valid Measures for Theoretical Models Using Survey Data. Journal of Business Research, 57, 125-141.

34. Robertson, M., \& Swan, J. (1996). The Role of Networks in the Diffusion of Technological Innovation. Journal of Management Studies, 33(3), 335- 361.

35. Riggins, F. J. \& Rhee, H.-S. (1998). Toward a Unified View of Electronic Commerce. Communications of the ACM, 41(10), 88-96.

36. Ruggles, R. (1997). Knowledge Tools: Using Technology to Manage Knowledge Better, Ernst \& Young Center for Business Innovation, New York: NY

37. Scott, J. E. (1998). Organizational Knowledge and the Intranet. Decision Support Systems, 23 , 3-17.

38. Smith, T. W. (1983). The Hidden 25 Percent: an Analysis of Nonresponse on the 1980 General Social Survey. Public Opinion Quarterly, 47, 386-404.

39. Spreitzer, G. M. (1995). Psychological Empowerment in the Work Place: Construct Definition, Measurement, and Validation. Academy of Management Journal, 1442-1465.

40. Stenmark, D. (2001). Leveraging tacit organizational knowledge. Journal of Management Information Systems, 17(3), 9-24.

41. Tampoe, M (1996). Motivating Knowledge workers - the challenge for the 1990s. In: Myers, P.S. (ed.), Knowledge Management and Organizational Design, Boston: MS, Butterworth-Heinemann, 179-190.

42. Thomas, K.W. \& Velthouse B.A. (1990). Cognitive Elements of Empowerment: An "Interpretive" Model of Intrinsic Task Motivation. Academy of Management Review, 15(4), 666-681.

43. Tissen, R., Andriessen, D. \& Lekanne Deprez, F. (1998). Value-based Knowledge Management: Creating the 21st century company: knowledge intensive, people rich, Amsterdam, Addison-Wesley Longman

44. Torkzadeh, G. \& Doll, W. J. (1999). The development of a tool for measuring the perceived impact of information technology on work. Omega, 27, 327-339

45. Tuomi, I. (2000). Data is more than knowledge: Implications of the reversed knowledge hierarchy for knowledge management and organizational memory. Journal of Management Information Systems, 16(3), 103-118

46. Van den hoof, B. \& De Leeuw van Weenen, F. (2004). Committed to Share: Commitment and CNC Use as Antecedents of knowledge Sharing. Knowledge and Process Management, 11(1), 13-24.

47. Venkatesh V. (2000). Determinants of Perceived Ease of Use: Integrating Control, Intrinsic Motivation, and Emotion into the Technology Acceptance Model. Information Systems Research, 11(4), 342-365.

48. VonKrogh, G. (1998). Care in knowledge creation. California Management Review, 40, $133-153$.

49. Vroom, V.H. (1964). Work and Motivation, New York, Wiley. 
Appendix A: Measurement Items for Task Knowledge and Performance Outcomes

List 3 most frequently used software applications:

\author{
1. \\ 2. \\ 3.
}

\title{
IT Support
}

The above applications were helpful in...

1. PRIT1 sharing my insights

2. PRIT2 communicating what I know

3. PRIT3 sharing my ideas

4. PRIT4 communicating with other people

\section{Knowledge Sharing}

During the assignment/project/work I have...

1. KSHR1 shared my insights with others

2. KSHR2 shared my know-how with others

3. KSHR3 shared my knowledge with others

4. KSHR4 shared my work-related knowledge with others

\section{Intrinsic Motivation}

During the assignment/project/work...

1. IMOT1 the work I did was important to me

2. IMOT2 my job activities were personally meaningful to me

3. IMOT3 the work I did was meaningful to me 
NOTES 